\title{
MYELODYSPLASTIC SYNDROMES (MDS)
}

\author{
Neysimelia Costa Villela ${ }^{1}$, Patrícia Shimoda Ikeuti ${ }^{2}$, Simone de Castro Resende Franco ${ }^{3}$, Roseane \\ Vasconcelos Gouveia ${ }^{4}$, Gustavo Zamperlini ${ }^{4}$, Luiz Fernando Lopes
}

\author{
1. Barretos Cancer Hospital, Barretos, SP, Brazil. \\ 2. Instituto de Oncologia Pediátrica IOP/GRAACC/UNIFESP, São Paulo, SP, Brazil. \\ 3. Hospital da Criança de Brasília José de Alencar. Brasília, DF, Brazil \\ 4. Hospital Samaritano, São Paulo, SP, Brazil
}

Correspondence to: ncvillela@hotmail.com

MDS in children is a rare group of hematopoietic stem cell clonal disorder, with an annual incidence of 1 to 4 cases per million. Some peculiarities of MDS in childhood are associated with previous exposure to cytotoxic agents, hereditary bone marrow failure syndromes, or genetic predisposition syndromes.

HLA typing and the search for a compatible donor must be carried out upon diagnosis, for all patients. When the potential donor belongs to the family, it is important that the same genetic changes present in the patient are ruled out, in addition to the complete hematological evaluation with complete blood count, myelogram, bone marrow biopsy and karyotype, to rule out incipient MDS. ${ }^{2}$

\section{REFRACTORY CYTOPENIA OF CHILDHOOD}

It is the most common subtype of MDS in the pediatric population. In contrast to adults, who usually have isolated anemia, hematological manifestations in children often include thrombocytopenia and/or neutropenia. ${ }^{3}$

Patients without an unfavorable karyotype can keep the disease stable for a long time. Thus, in the absence of transfusion dependence or severe neutropenia, a careful observation strategy without treatment is recommended. ${ }^{1,4,5}$

Allogeneic HSCT, with the best available donor, is indicated in the following situations:

a) Presence of monosomy of chromosome 7 or deletion of the long arm of chromosome 7, due to the high risk of progression to more advanced forms of the disease and acute myeloid leukemia (AML); $1,4,6$

b) Complex karyotype (3 or more chromosomal aberrations, at least one structural), despite the unfavorable prognosis even with $\mathrm{HSCT}^{1,1,7}$ c) Sustained neutropenia $(<1000 / \mathrm{mm} 3)$ or need for transfusion. ${ }^{1,3}$

Patients with hypocellular bone marrow and without an unfavorable karyotype can benefit from a reduced intensity conditioning regimen. For the others, a myeloablative regimen is indicated. 8,9

In the absence of a suitable donor, immunosuppressive treatment with ATG and cyclosporine may be an option for patients with hypocellular bone marrow, without a bad prognosis karyotype. However, these patients remain at risk of relapse and clonal evolution and need careful surveillance..$^{10,11}$

\section{REFRACTORY ANEMIA WITH RING SIDEROBLASTS}

In children with refractory anemia with ring sideroblasts and the presence of cell vacuolization, it is essential to investigate mitochondriopathies. If this diagnosis is confirmed, there is no indication for performing $\mathrm{HSCT}$, as hematological changes regress spontaneously over time and transplantation does not change the sad natural history of the disease.

\section{ADVANCED MDS}

The treatment of children diagnosed with MDS with excess blasts, with or without signs of transformation and with evolutionary AML of MDS remains a major challenge. Allogeneic HSCT is the only curative treatment, although the data published in the literature generally include a small number of patients, heterogeneously transplanted. ${ }^{1,4}$

In the largest cohort of children with advanced MDS reported to date, the European group (EWOG-MDS) demonstrated an overall 5-year survival of $63 \%$ in 97 patients undergoing allogeneic HSCT with the same myeloablative conditioning regimen (busulfan, cy- 
clophosphamide and melphalan). Age over 12 years at HSCT, interval between diagnosis and HSCT over 4 months and occurrence of acute or chronic GvHD were associated with increased transplant-related mortality (TRM). Patients with evolutionary AML of MDS had high rates of relapse.

A more recent update of the EWOG-MDS data, with the same conditioning regimen mentioned above, showed a decrease in TRM, particularly in the adolescent subgroup. The update also showed that eventfree survival for patients who received a transplant from an identical HLA sibling or from an unrelated HLA donor in high resolution $9 / 10$ or $10 / 10$ was similar. ${ }^{1,4}$ The presence of a complex karyotype is strongly associated with a poor prognosis. ${ }^{12}$

Pre-HSCT treatment remains a controversial issue. If, on the one hand, it would be desirable to reduce the percentage of blasts, on the other hand, the use of chemotherapy has been associated with significant toxicity. In addition, there is little data on the best scheme to be used. The European group suggests that intensive chemotherapy should not be used routinely, however, 1 cytoreductive chemotherapy cycle can be considered for children with ${ }^{3} 20 \%$ of bone marrow blasts, in an attempt to reduce relapse after HSCT. ${ }^{1}$ There is little data on the efficacy of hypomethylating agents in pediatric MDS, but 2 retrospective studies with a small number of patients have pointed to a possible role of azacitidine as a pre-HSCT bridge. ${ }^{13-14}$

\section{MDS SECONDARY TO THERAPY}

Specific reports of children with MDS and AML secondary to therapy generally include a limited number of patients. Allogeneic HSCT is indicated, but the evolution is generally unfavorable, with overall survival between 13 and $35 \%$, despite HSCT. ${ }^{1,4,15,16} \mathrm{~A}$ short time between diagnosis and HSCT was identified as an important factor for better survival of these patients. ${ }^{17}$

\begin{tabular}{c|c|c|c}
\hline HSCT indication & $\begin{array}{c}\text { Allogeneic } \\
\text { HSCT }\end{array}$ & $\begin{array}{c}\text { Autologous } \\
\text { HSCT }\end{array}$ & Notes \\
\hline Refractory cytopenia of childhood & $\mathrm{C}$ & $\mathrm{N}$ & $\begin{array}{c}\text { For patients without unfavorable karyotype, without } \\
\text { transfusion dependence or severe neutropenia, a } \\
\text { careful observation strategy without treatment is } \\
\text { recommended. }\end{array}$ \\
\hline Advanced MDS & $\mathrm{S}$ & $\mathrm{N}$ & $\mathrm{N}$ \\
\hline MDS secondary to therapy & $\mathrm{S}$ & & \\
\hline
\end{tabular}

\section{S: Standard of care \\ C: Standard of care, clinical evidence available \\ $\mathrm{R}$ : Standard of care, rare indication \\ D: Developmental}

$\mathrm{N}$ : Not generally recommended 


\section{REFERENCES}

1. Locatelli F, Strahm B. How I treat myelodysplastic syndromes of childhood. Blood. 2018;131(13):1406-1414.

doi:10.1182/ blood-2017-09-765214.

2. Seber A, Villela NC, Gouveia RV et al. Tratamento com transplante de medula óssea, capítulo 17, 283-294. In: Lopes LF. Mielodisplasia em pediatria. São Paulo: Lemar Goi editora; 2019.

3. Hasle H. Myelodysplastic and myeloproliferative disorders of childhood. Hematology Am Soc Hematol Educ Program. 2016;2016(1):598-604. doi:10.1182/asheducation-2016.1.598.

4. Galaverna F, Ruggeri A, Locatelli F. Myelodysplastic syndromes in children. Curr Opin Oncol. 2018;30(6):402-408. doi:10.1097/ CCO.0000000000000488.

5. Hasegawa D, Chen X, Hirabayashi S, et al. Clinical characteristics and treatment outcome in 65 cases with refractory cytopenia of childhood defined according to the WHO 2008 classification. Br J Haematol. 2014;166(5):758-766. doi:10.1111/bjh.12955.

6. Kardos G, Baumann I, Passmore SJ, et al. Refractory anemia in childhood: a retrospective analysis of 67 patients with particular reference to monosomy 7. Blood. 2003;102(6):1997-2003. doi:10.1182/blood-2002-11-3444.

7. Strahm B, NollKe P, Zecca M, et al. Hematopoietic stem cell transplantation for advanced myelodysplastic syndrome in children: results of the EWOG-MDS 98 study. Leukemia. 2011;25(3):455462. doi:10.1038/leu.2010.297.

8. Inagaki J, Fukano R, Kurauchi K, et al. Hematopoietic stem cell transplantation in children with refractory cytopenia of childhood: single-center experience using high-dose cytarabine containing myeloablative and aplastic anemia oriented reduced-intensity conditioning regimens. Biol Blood Marrow Transplant. 2015;21(3):565-569. doi:10.1016/j.bbmt.2014.12.003.

9. Strahm B, Locatelli F, Bader P, et al. Reduced intensity conditioning in unrelated donor transplantation for refractory cytopenia in childhood. Bone Marrow Transplant. 2007;40(4):329-333. doi:10.1038/sj.bmt.1705730.
10. Sloand EM, Wu CO, Greenberg P, et al. Factors affecting response and survival in patients with myelodysplasia treated with immunosuppressive therapy. J Clin Oncol. 2008;26(15):25052511. doi:10.1200/JCO.2007.11.9214.

11. Yoshimi A, Baumann I, Fuhrer M, et al. Immunosuppressive therapy with anti-thymocyte globulin and cyclosporine $A$ in selected children with hypoplastic refractory cytopenia. Haematologica. 2007;92(3):397-400. doi:10.3324/haematol.10683.

12. Göhring G, Michalova K, Beverloo HB, et al. Complex karyotype newly defined: the strongest prognostic factor in advanced childhood myelodysplastic syndrome. Blood. 2010;116(19):37663769. doi:10.1182/blood-2010-04-280313.

13. Cseh AM, Niemeyer CM, Yoshimi A, et al. Therapy with low-dose azacitidine for MDS in children and young adults: a retrospective analysis of the EWOG-MDS study group. Br J Haematol. 2016;172(6):930-936. doi:10.1111/bjh.13915.

14. Waespe N. Response to treatment with azacitidine in children with advanced myelodysplastic syndrome prior to hematopoietic stem cell transplantation. Haematologica. 2016;101(12):15081515. doi:10.3324/haematol.2016.145821.

15. Aguilera DG, Vaklavas C, Tsimberidou AM, et al. Pediatric therapy-related myelodysplastic syndrome/acute myeloid leukemia: the MD Anderson Cancer Center experience. J Pediatr Hematol Oncol. 2009;31(11):803-811. doi:10.1097/ MPH.0b013e3181ba43dc.

16. Woodard P, Barfield R, Hale G, et al. Outcome of hematopoietic stem cell transplantation for pediatric patients with therapy-related acute myeloid leukemia or myelodysplastic syndrome. Pediatr Blood Cancer. 2006;47(7):931-935. doi:10.1002/pbc.20596.

17. Maher OM, Silva JG, Wu J, et al. Outcomes of children, adolescents, and young adults following allogeneic stem cell transplantation for secondary acute myeloid leukemia and myelodysplastic syndromes-The MD Anderson Cancer Center experience. Pediatr Transplant. 2017;21(3). Doi: 10.1111/petr.12890. 